\title{
Modeling the Influence of Dust-Removing Extraction Fan's Parameters on the Dust Control Effects in the Tunnel
}

\author{
Qingguo Wang \\ School of Safety Engineering, China University of Mining and Technology \\ Xuzhou 221116, China
}

Tel: 86-151-6211-6897 E-mail: wang_qing_guo@126.com

Deming Wang (Corresponding author)

School of Safety Engineering, China University of Mining and Technology

Xuzhou 221116, China

Tel: 86-139-5223-9019Ｅ-mail: wang_dmcumt@163.com

Hetang Wang

School of Safety Engineering, China University of Mining and Technology

Xuzhou 221116, China

Tel: 86-151-5001-3592Ｅ-mail: whtcumt@126.com

Received: April 21, 2016 Accepted: May 16, 2014

doi:10.5296/emsd.v5i2.9627ＵRL: http://dx.doi.org/10.5296/emsd.v5i2.9627

\begin{abstract}
In the process of comprehensive mechanized tunnelling in coal mines, forced ventilation is usually adopted to supply air in China. But this ventilation mode could cause the dust rise and diffuse more easily, which has threaten the mine workers' health seriously. To solve this problem, dust-removing extraction fan is generally used to suck and purify dusty air in mines. However, the optimal arrangement scheme for dust control is rarely systematically studied. In
\end{abstract}


this paper, we took the tunnel in Donghuantuo Mine as an example and use CFD simulation technology to analyze the dust migration law and dust control effects under different conditions. An unsteady state solution is used to simulate the process and the simulation have realized the visualization of dust migration process with time and the results are as follows. Firstly, it's better for dust control to arrange the inlet of the dust-removing extraction fan to the air return side rather than to the center of the tunnel. Secondly, the dust control effects decrease with the distance between inlet of the dust-removing extraction fan and heading face increases. Thirdly, as the amount of air suction is larger than air supply, the dust control efforts would get worse. Field test results are similar with that obtained from simulation under the optimal arrangement, which proves the reliability of simulation.

Keywords: Dust, Ventilation, CFD simulation, Dust-removing extraction fan

\section{Introduction}

Comprehensive mechanized tunnelling technology possesses the advantages of high tunneling speed, which has enhanced production efficiency in coal mines; however, large amounts of dust are produced when a roadheader is operating, and accounts for more than $80 \%$ of all dust produced at the tunneling face. More seriously, forced ventilation is usually adopted to supply air in China, which could cause the dust rise and diffuse more easily. The high concentrations of suspended dust are a ready cause of pneumoconiosis in workers. The conventional method of dust control at the tunneling face is the use of water spray to capture dust particles in the air (Han, Wang, Jiang, \& Zhu, 2014). It is difficult to suppress the dust well in this way because of the large quantity of dust and its rapid diffusion when the roadheader is operating (Kurnia, Sasmito, \& Mujumdar, 2014). In order to improve the dust control effects, dust-removing extraction fan is generally used to suck and purify dusty air in China's mines, which has achieve better effects compared with water spray (Ma, 2012).

However, the optimal arrangement is rarely systematically studied. In this paper, we took the tunnel in Donghuantuo Mine of China as an example and use CFD simulation technology to analyze the dust migration law and dust control effects under different conditions. As a whole tunneling time is usually several minutes due to the complicated working conditions, the dust distribution in the tunnel is actually changing in real time. Steady-state setting is usually adopted as using traditional method to simulate the dust distribution, which fluid physical parameters don't change with time and can't reflect the process that the dust migration with time (Qin, Zhang, \& Zhang, 2011; Du, Wang, \& Jiang, 2010). This solution is easy to appear such abnormal physical phenomena similar to the Kaman vortex street disturbed flow. To solve this problem, an unsteady state setting is used to simulate the process.

\section{Numerical Simulation Method}

\subsection{Physical Model}

In order to simulate dust migration under different conditions, a model is made with Gambit according to the actual size of working face. This model is based on the actual conditions of -690 main haulage tunnel of Donghuantuo Coal Mine, driven by roadheader EBZ200. The actual supplied airflow of this tunnel is $300 \mathrm{~m}^{3} / \mathrm{min}$. The simulative tunnel is $50 \mathrm{~m} \mathrm{long}$, and 


\section{Macrothink}

Environmental Management and Sustainable Development

ISSN 2164-7682 2016, Vol. 5, No. 2

its cross section is $5.5 \mathrm{~m}$ wide and $3.8 \mathrm{~m}$ high. The main body of roadheader, located at a distance of $1.5 \mathrm{~m}$ from the face, measures $10 \mathrm{~m}$ (Length) $3.6 \mathrm{~m}$ (Width) $1.8 \mathrm{~m}$ (Height). The forced ventilation tubing is located $7 \mathrm{~m}$ to the face, with a size of $0.8 \mathrm{~m}$ diameter and $0.2 \mathrm{~m}$ far to sidewall and $2.5 \mathrm{~m}$ far to floor. The simplified tunnel model is shown in Figure 1. Based on conditions mentioned above, tetrahedron filling was used for unstructured mesh generation of the calculated area. Figure 2 shows the mesh generation of physical model.

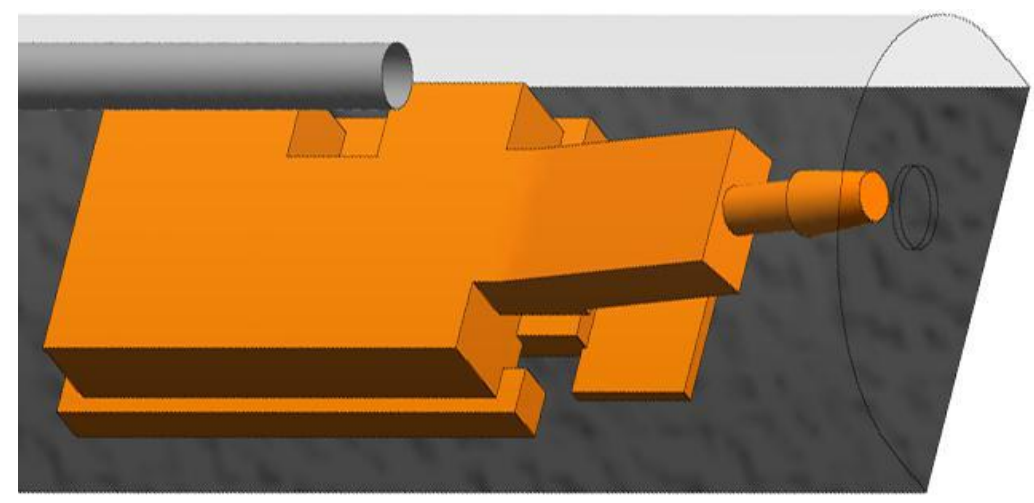

Figure 1. The simplified tunnel model

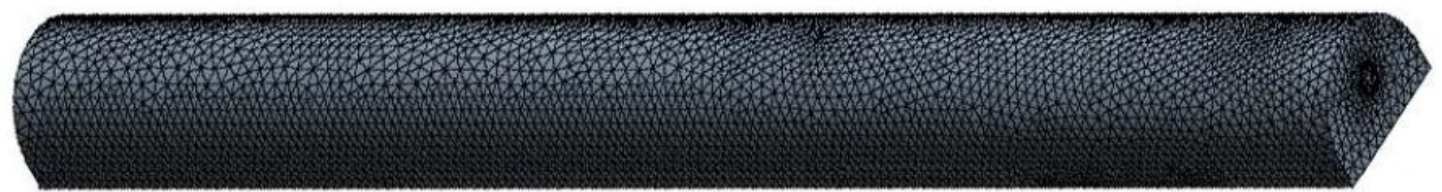

(a) The surface mesh

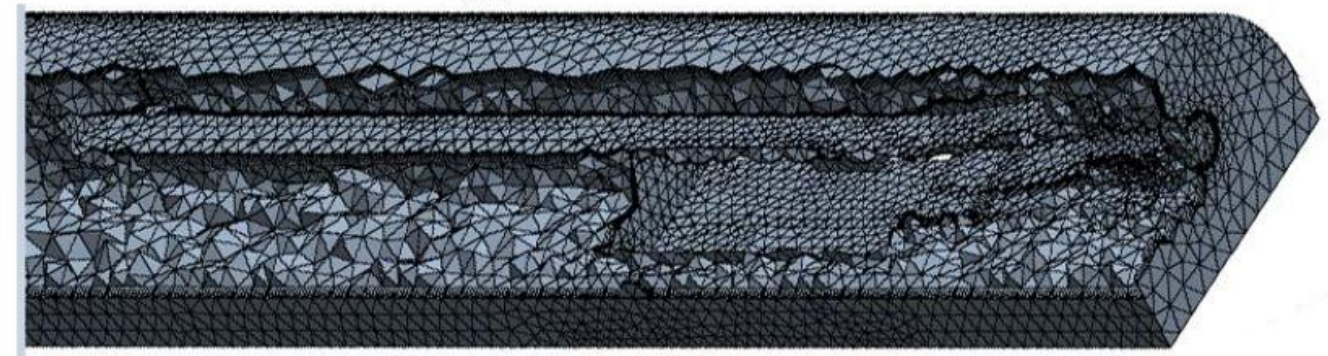

(b) The internal mesh

Figure 2. Mesh generation of physical model

\subsection{Mathematical Model}

The dust particle is regarded as discrete phase and the air as continuous phase. The Lagrangian discrete phase model in Fluent follows the Euler-Lagrange approach and the dispersed phase is solved by tracking a large number of particles through the calculated flow field. The unsteady state setting is reflected in the control equations of fluid and continuous phase follows the Navier-Stokes equations (Kang, \& Guo, 2006; Niu, Jiang, \& Tian, 2011).

\subsubsection{Mathematical Model of Continuous Phase}

As the unsteady state setting is used in the simulation, the momentum conservation equations 
are as follows:

$$
\begin{aligned}
& \frac{\text { 抖 }(r u)}{\text { 抖 } t}+\operatorname{div}(r u \vec{V})=\operatorname{div}(\text { mgradu })-\frac{p}{x}+S_{u} \\
& \frac{\text { 抖 }(r v)}{\text { 抖 } t}+\operatorname{div}(r u \vec{V})=\operatorname{div}(\operatorname{mgrad} v)-\frac{p}{y}+S_{v} \\
& \frac{\text { 抖 }(r w)}{\text { 抖 } t}+\operatorname{div}(r u \vec{V})=\operatorname{div}(\operatorname{mgrad} w)-\frac{p}{z}+S_{w}
\end{aligned}
$$

Where $\operatorname{grad}()=\frac{\text { 抖 }()}{\text { 抖 }}+\frac{()}{y}+\frac{?()}{? z} ; r$ is fluid density; $\vec{V}$ is fluid velocity; $u, v, w$ the velocity components on three axes for micro unit; $p$ the pressure on the fluid micro unit. and $S_{u}, S_{v}, S_{w}$ the general source items for kinetic energy conservation.

\subsubsection{Mathematical Model of Dispersed Phase}

The dust particles in the model have the following simplified assumptions.

- Dust particles in the airflow are considered to be spheres with the same density.

- The impact of the collision between dust particles is ignored and the collision between dust particles and the wall is only considered.

- The influence that the temperature field to the airflow is ignored.

This force balance equates the particle inertia with the forces acting on the particle, which is shown as(Huang, Yue, \& Zheng, 2008; Shi, Ma, \& Zhang, 2013)

$$
\frac{d u_{p}}{d t}=F_{D}\left(u-u_{p}\right)+\frac{g_{i}\left(r_{p}-r\right)}{r_{p}}+F_{i} \quad i=(x, y, z)
$$

where $F_{D}\left(u-u_{p}\right)$ is the drag force per unit particle mass; $u$ the gas phase velocity; $u_{p}$ the droplet velocity; $\mu$ the molecular viscosity of the gas; $\rho$ the gas density; $\rho_{p}$ the density of the droplet; $C_{D}$ the drag coefficient; and $d_{p}$ the droplet diameter. Re is the relative Reynolds number. $F_{D}$, Re and $C_{D}$ are shown as

$$
\begin{gathered}
F_{D}=\frac{18 m}{r_{P} d_{p}^{2}} \frac{C_{D} \operatorname{Re}}{24} \\
\operatorname{Re}=\frac{r d_{p}\left|u_{p}-u\right|}{m}
\end{gathered}
$$




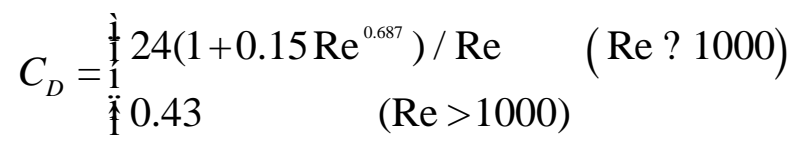

\subsection{Boundary Conditions}

The properties of ducting's inlet of the dust-removing extraction fan and the exit of tunnel are set as Escape, which defines that dust is separated from calculating area as it enters into dust-removing extraction fan or spread out of the exit of tunnel. The properties of walls of the roadheader, ducting and tunnel are set as Reflect, which define dust would continue to exist in the calculating area after the collision between dust and the walls. The detailed parameters are shown in Table 1.

Table 1. Detailed parameters in the simulation

\begin{tabular}{|c|c|}
\hline Parameters & Settings \\
\hline Time step & $0.05 \mathrm{~s}$ \\
\hline The coupling calculation & Active \\
\hline Continuous phase calculation steps & 1 \\
\hline Turbulent particle dispersion & Stochastic tracking \\
\hline Gravitational acceleration & $9.8 \mathrm{~m} / \mathrm{s}^{2}$ \\
\hline Dust source type & Surface \\
\hline Dust mass flow & $0.008 \mathrm{~kg} / \mathrm{s}$ \\
\hline Suction airflow of the dust-removing extraction fan & $240 \mathrm{~m}^{3} / \mathrm{min}$ \\
\hline
\end{tabular}

\section{Simulation Contents}

As shown in Table 2, to study the impact of the locations of the dust-removing extraction fan's inlet on dust control effects, the conditions that placing the dust-removing extraction fan's inlet to the center and to the air return side of the tunnel are simulated respectively. In each condition, for exploring the influence of distance between inlet of the dust-removing extraction fan and heading face on the dust control effects, three different distances are compared.

Table 2. The locations of the dust-removing extraction fan's inlet

\begin{tabular}{|l|l|l|}
\hline Type & $\begin{array}{l}\text { The locations of the dust-removing } \\
\text { extraction fan's inlet }\end{array}$ & $\begin{array}{l}\text { Distance between inlet of the dust-removing extraction fan } \\
\text { and heading face L }(\mathrm{m})\end{array}$ \\
\hline 1.1 & The center of the tunnel & \\
\hline
\end{tabular}




\begin{tabular}{|c|c|c|}
\hline 1.2 & & 3.5 \\
\hline 1.3 & & 5 \\
\hline 2.1 & \multirow[t]{3}{*}{ The air return side of the tunnel } & 2 \\
\hline 2.2 & & 3.5 \\
\hline 2.3 & & 4 \\
\hline
\end{tabular}

In the actual situation of tunneling, the cutting process starts after the airflow field formed normally. So during the simulation, there is only opening ventilation facilities without cutting in the first 20 seconds, then the cutting begin.

\section{Results and Discussion}

\subsection{Without Dust-Removing Extraction Fan}

We can obtain from Figure 3 and Figure 4 that the migration paths of dust with time are dust sources - air return side - upper space of the roadheader - air intake side or dust sources return air side - the back of tunnel. As the existence of the roadheader and the cycle airflow, the dust concentration in the front of tunnel is high, which is usually above $1000 \mathrm{mg} / \mathrm{m}^{3}$, and there is no difference between the air intake side and the air return side in the 60th seconds. At the back of tunnel, there are not large equipments and the space is large, so the dust can spread easily and the dust concentration is relatively low; but the dust is concentrated in the return airflow.
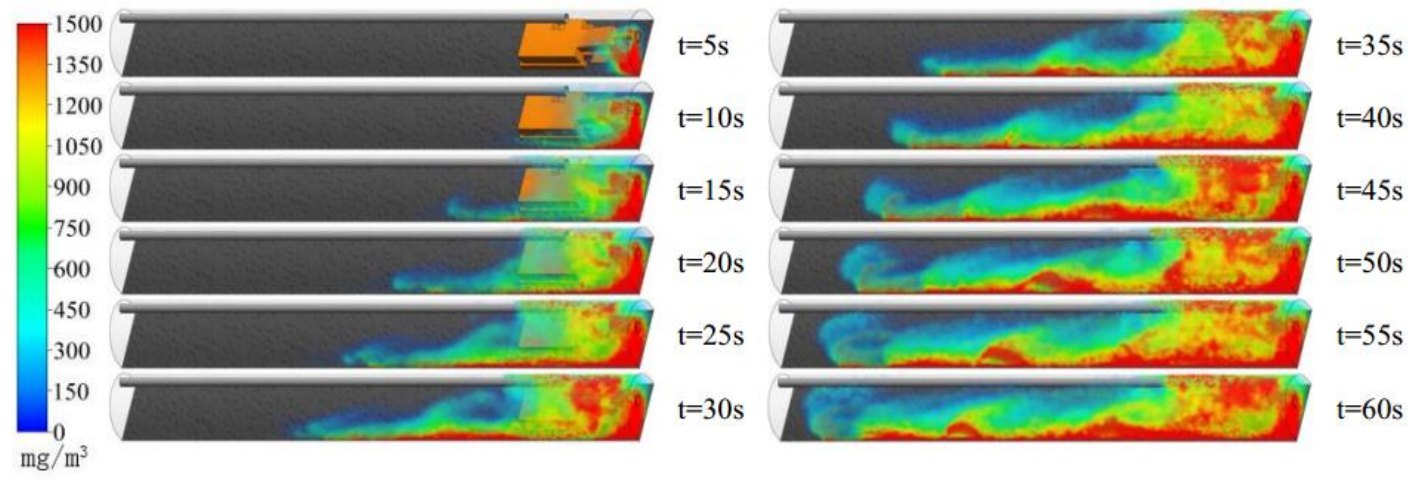

Figure 3. Dust migration process without dust-removing extraction fan 


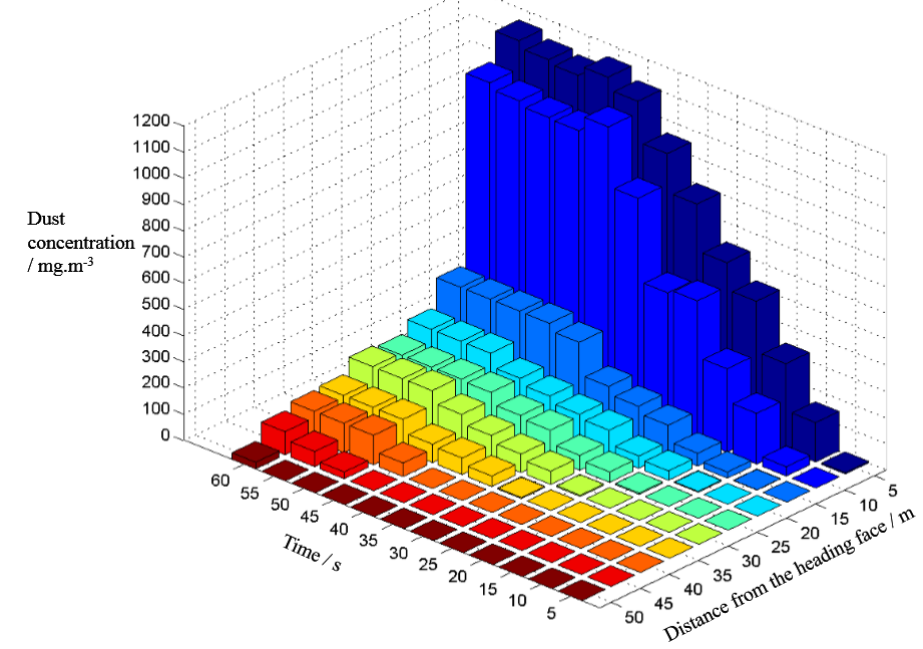

Figure 4. The dust concentration data of tunnel with time

\subsection{The Dust-Removing Extraction Fan'S Inlet Is Located at the Center of Tunnel}

What we can obtain from Figure 5 and Figure 6 are as follows.

(1) As the dust-removing extraction fan's inlet is located at the center of tunnel, the cycle airflow would be increased after the opening of the dust-removing extraction fan and the dust would be captured as it's migrated from the air return side to the air intake side, which reduces the dust concentration significantly.

(2) The purified airflow injects into the tunnel at the speed of $240 \mathrm{~m}^{3} / \mathrm{min}$, diluting the dust in the tunnel and taking the dust to a more distant place in a much faster speed at the same time, which accelerate the spread of dust migration and reduce the density of dust.

(3) As the effective absorption distance of the dust-removing extraction fan is limited, with L increases, dust could not captured easily and the dust control effects are not ideal.
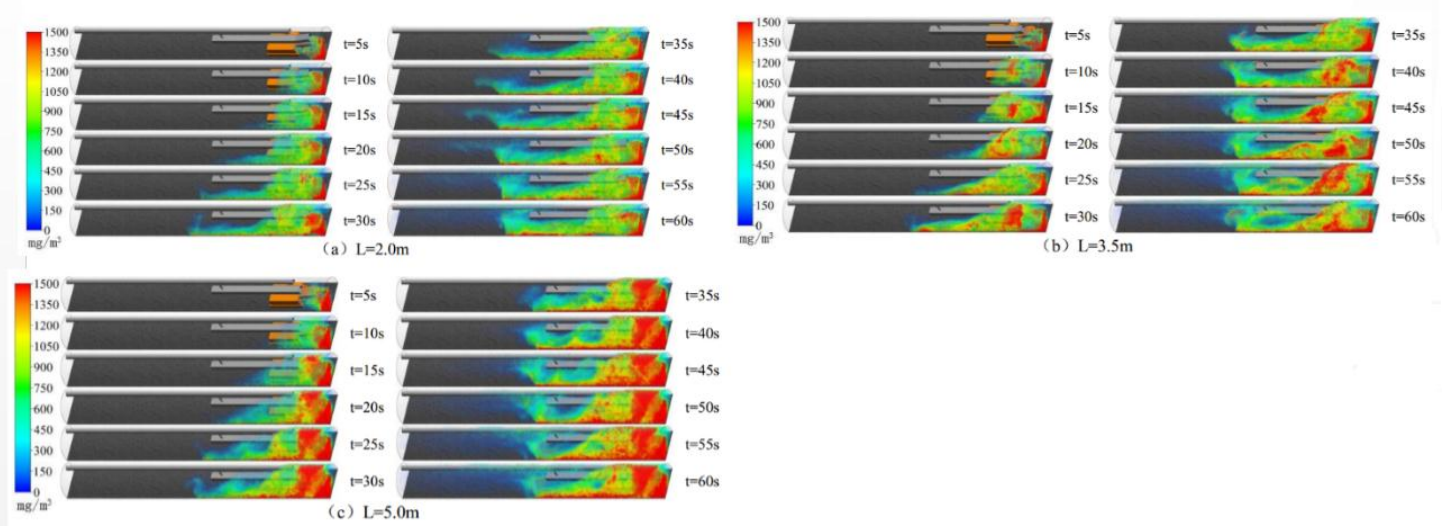

Figure 5. Dust migration process with dust-removing extraction fan's inlet located at the center of tunnel 


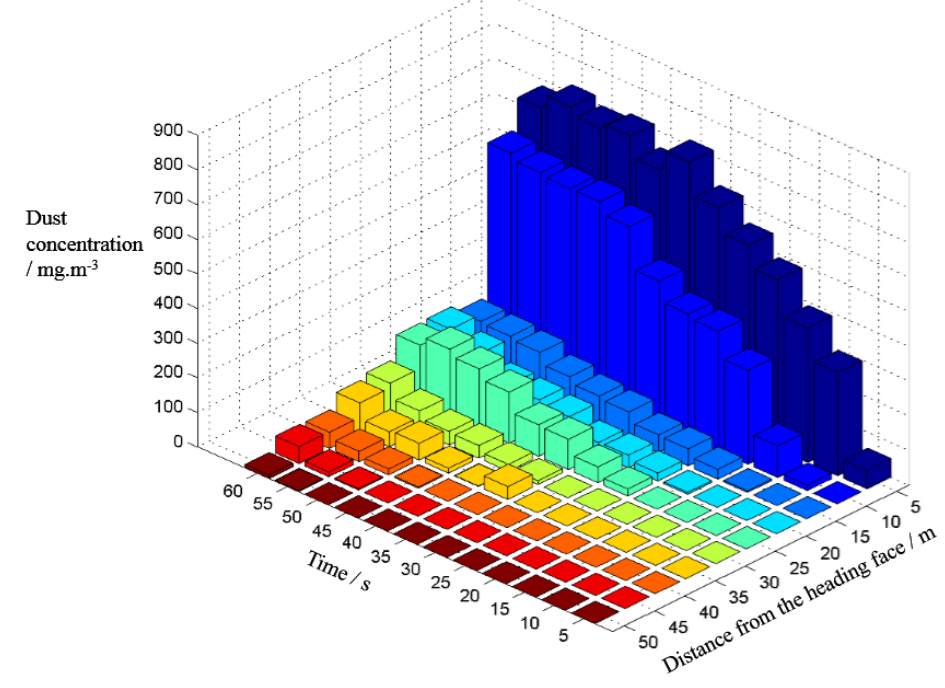

Figure 6. The dust concentration data of tunnel with time $(\mathrm{L}=2 \mathrm{~m})$

\subsection{The Dust-Removing Extraction Fan'S Inlet Is Located at the Air Return Side of Tunnel}

What we can obtain from Figure 7 and Figure 8 are as follows.

(1) The dust concentration in the tunnel has been reduced significantly compared with the condition without the dust-removing extraction fan.

(2) The arrangement of installing the suction inlet of dust-removing extraction fan at the air return side of tunnel reduces the cycle airflow and makes more dust move with the return airflow to the back of tunnel compared with the way that dust-removing extraction fan's inlet located at the center of tunnel. And in the process of migration, more dust would be captured by the dust-removing extraction fan.

(3) with L increases, dust could not captured easily and the dust control effects are not ideal, which is same with the above way.
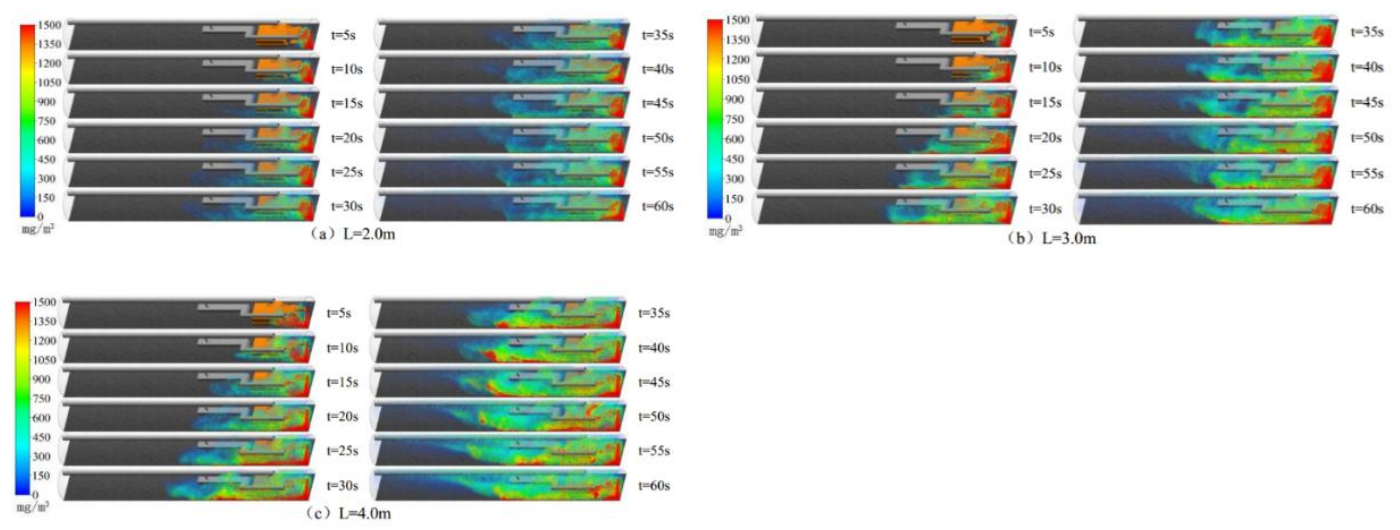

Figure 7. Dust migration process with dust-removing extraction fan's inlet located at the air return side of tunnel 


\section{Macrothink

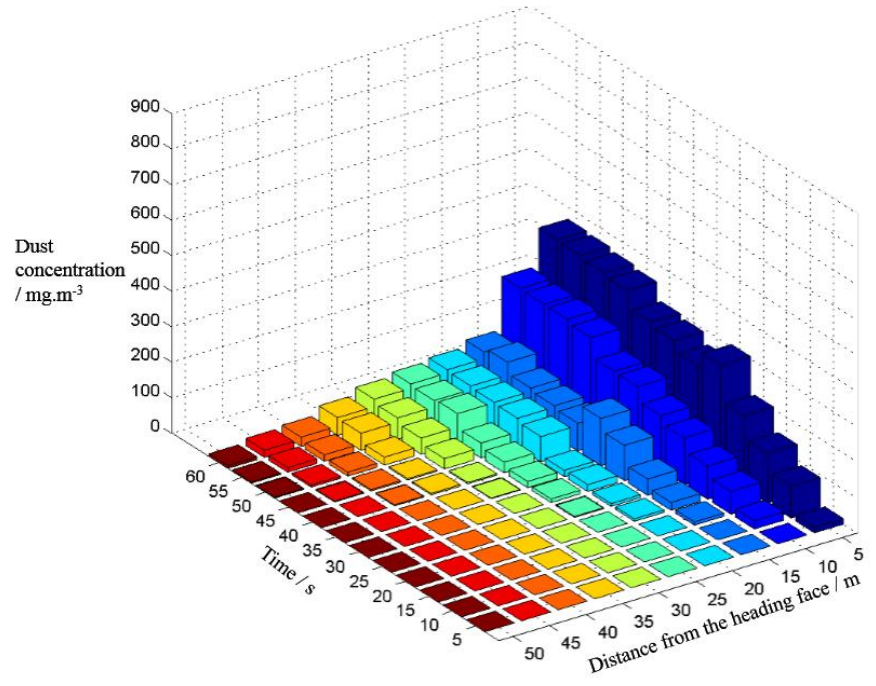

Figure 8 . The dust concentration data of tunnel with time $(\mathrm{L}=2 \mathrm{~m})$

\subsection{The Ratio of Supplied Airflow and Suction Airflow Is 0.8}

The ratio of supplied airflow and suction airflow is another characteristic parameter for mine dust control. The airflow field and dust transport are different under different ratios. It can be seen that from the above examples that the dust control effects are best as the inlet of the extraction fan is arranged in the air return side of tunnel $(\mathrm{L}=2.0 \mathrm{~m})$ when the ratio of supplied airflow and suction airflow is 1.25. Taking this kind of optimal arrangement as an example, keeping the compressed airflow unchanged $300 \mathrm{~m}^{3} / \mathrm{min}$ and increasing the airflow of dust-removing extraction fan from $240 \mathrm{~m}^{3} / \mathrm{min}$ to $375 \mathrm{~m}^{3} / \mathrm{min}$, dust migration and dust control effects under this situation would be discussed.

It can be seen from the Figure 9 and Figure 10 that as the ratio is 0.8 , the airflow in front of the outlet of the dust-removing extraction fan would move forward to the heading face causing most dust could not spread to the rear of the tunnel and not be diluted by fresh airflow. Although restricting dust in the front of tunnel can increase the amount of capturing dust for the dust-removing extraction fan, the working environment in the front of tunnel become worse than that as the ratio is 1.25 . As is shown in figure 8 , after cutting for 1 minute, the average dust concentration in the front of the tunnel has been more than $700 \mathrm{mg} / \mathrm{m}^{3}$ which is much higher than $365 \mathrm{mg} / \mathrm{m}^{3}$ at the pressure extraction ratio of 1.25 and it still has the trend to increase with the extension of cutting time. 

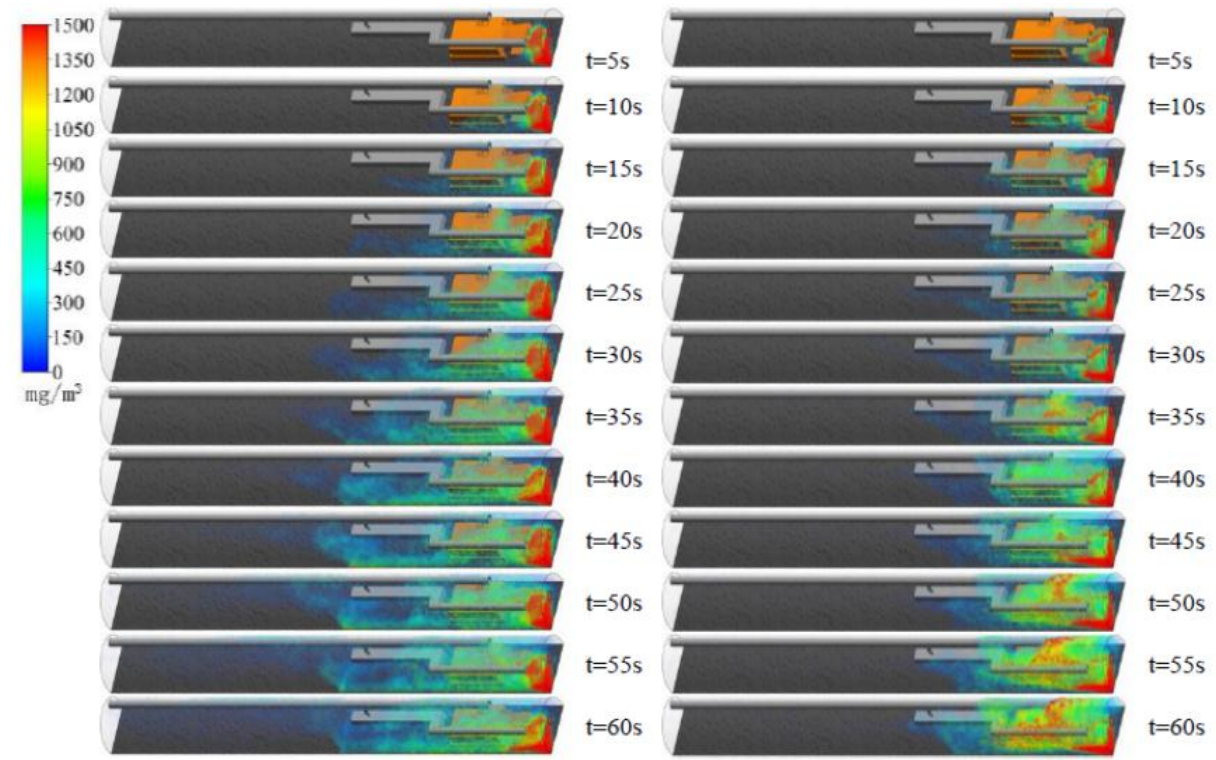

(a) supplied airflow : suction airflow $=1.25$

(b) supplied airflow : suction airflow $=0.8$

Figure 9. Comparison of dust migration process under different ratios

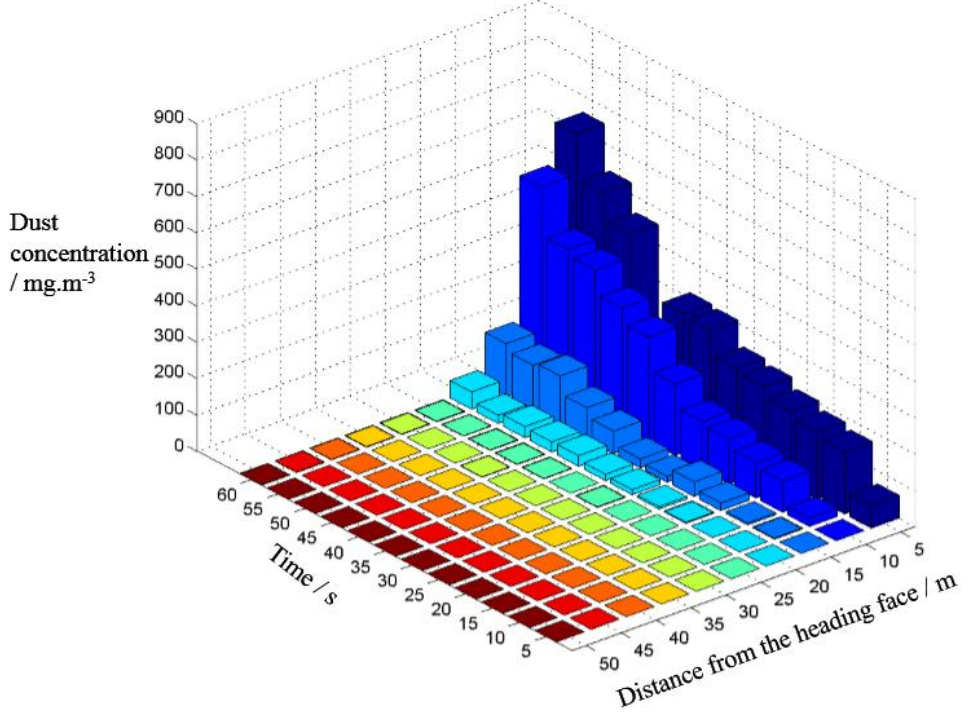

Figure 10. The dust concentration data of tunnel with time $(\mathrm{L}=2 \mathrm{~m})$

\section{Field Application}

The above simulation results show that as the dust-removing extraction fan's inlet is located at the air return side of tunnel and the distance from the heading face is $0.2 \mathrm{~m}$, the supplied airflow is $300 \mathrm{~m}^{3} / \mathrm{min}$ and suction airflow is $240 \mathrm{~m}^{3} / \mathrm{min}$, the dust control effects are best. After cutting 60 seconds, the dust control efficiency reaches $53.6 \%$.

To verify the simulation result, field testing was done according to the optimal arrangement at the driver's position. Three groups of measured data for the dust concentration of total dust (td) and respirable dust (rd) were obtained for three different conditions: (i) no dust 
suppression; (ii) water spray; and (iii) proposed method, as listed in Table 3. The test results show that the dust control efficiencies of dust-removing extraction fan achieved the results of $38.97 \%$ for td and $44.5 \%$ for $\mathrm{rd}$.

Table 3. Dust test data

\begin{tabular}{|c|c|c|c|c|c|c|}
\hline \multirow[t]{2}{*}{ Driver position } & \multicolumn{2}{|c|}{$\begin{array}{l}\text { Without any } \\
\text { solution }\end{array}$} & \multicolumn{2}{|c|}{ Water spray } & \multicolumn{2}{|c|}{ Dust-removing extraction fan } \\
\hline & $\mathrm{td}$ & rd & $\mathrm{td}$ & rd & $\mathrm{td}$ & rd \\
\hline \multirow{3}{*}{ Measured data $\left(\mathrm{mg} / \mathrm{m}^{3}\right)$} & 1017.8 & 512.3 & 807.4 & 407.8 & 636.3 & 313.5 \\
\hline & 1125.4 & 647.1 & 815.1 & 415.6 & 674.9 & 324.3 \\
\hline & 1089.6 & 562.2 & 791.2 & 398.3 & 661.7 & 318.5 \\
\hline Average concentration $\left(\mathrm{mg} / \mathrm{m}^{3}\right)$ & 1077.6 & 573.9 & 804.6 & 407.2 & 657.6 & 318.8 \\
\hline
\end{tabular}

Due to the measured position is limited and the measured results are the average value for long time sampling, the simulated results and measured results are not perfectly matched. But the similar results can also be used in a certain extent, shows that the dust control efficiencies of dust-removing extraction fan are $40 \% \sim 50 \%$

\section{Conclusion}

1) The dust migration process and dust control effects are simulated under different conditions using unsteady DPM model. Field testing was done according to the optimal arrangement at the driver's position, the similar results shows that the dust control efficiencies of dust-removing extraction fan are $40 \% \sim 50 \%$.

2) As the ratio of supplied airflow and suction airflow is 1.25 , cycle airflow would appear and the migration path of dust are dust sources - air return side - upper space of the roadheader air intake side; the cycle airflow could be enhanced and more dust would return to the air intake side and the driver's position when the dust-removing extraction fan's inlet is located at the center of tunnel compared with the dust-removing extraction fan's inlet is located at the air return side of tunnel. The dust control effects decrease with the distance between inlet of the dust-removing extraction fan and heading face increases.

3) As the ratio of supplied airflow and suction airflow is 0.8 , the airflow in front of the outlet of the dust-removing extraction fan would move forward to the heading face causing most dust could not spread to the rear of the tunnel and not be diluted by fresh airflow. Although restricting dust in the front of tunnel can increase the amount of capturing dust for the dust-removing extraction fan, the working environment in the front of tunnel become worse than that as the ratio is 1.25 .

\section{Acknowledgements}

This work has been funded by the Fundamental Research Funds for the Central Universities 
(2015XKMS009) and the National Natural Science Foundation of China (51504249, 51474216) and PAPDA (A Project Funded by the Priority Academic Program Development of Jiangsu Higher Education Institutions).

\section{References}

Du, C., Wang, F. H., \& Jiang, Z. A. (2010). Numerical simulations of dust distribution in a fully mechanized excavation face with far-pressing-near-absorption ventilation. Chinese Journal of Engineering, 32, 957-961. http://doi.org/10.13374/j.issn1001-053x.2010.08.027

Han, F. W., Wang, D. M., Jiang, J. X., \& Zhu X. L. (2014). Modeling the influence of forced ventilation on the dispersion of droplets ejected from roadheader-mounted external sprayer. International Journal of Mining Science and Technology, 24, 129-135. http://doi.org/10.1016/j.ijmst.2013.12.022

Huang, N., Yue, G. W., \& Zheng, X. J. (2008). Numerical simulations of a dust devil and the electric field in it. Journal of Geophysical Research, 113, 203. http://doi.org/10.1029/2008JD010182

Kang, L. Q., \& Guo, L. j. (2006). Eulerian-Lagrangian simulation of Aeolian sand transport. Powder Technology, 162, 111-120. http://doi.org/10.1016/j.powtec.2005.12.002

Kurnia, J. C., Sasmito, A. P., \& Mujumdar, A. S. (2014). Dust dispersion and management in underground mining faces. International Journal of Mining Science and Technology, 24, 39-44. http://doi.org/10.1016/j.ijmst.2013.12.007

Ma, C. M. (2012). Application of Dust Ventilator with Wet Screw Chord at Fully Mechanized $\begin{array}{lllll}\text { Driving } & \text { Face. } & \text { Coal } & \text { Technology, } & 31,\end{array}$ http://doi.org/10.3969/j.issn.1008-8725.2012.12.034

Niu, W., Jiang, Z. A., \& Tian, D. M. (2011). Numerical simulation of the factors influencing dust in drilling tunnels: its application. Mining Science and Technology (China), 21, 11-15. http://doi.org/10.1016/j.mstc.2010.12.009

Qin, Y. P., Zhang, M. M., \& Zhang, L. J. (2011). Numerical simulation of dust migration and study on dust removal modes with the forced ventilation shunt in a fully mechanized workface. Chinese Journal of Engineering, 33, 790-794. http://doi.org/10.13374/j.issn1001-053x.2011.07.008

Shi, G. H., Ma, W., \& Zhang, J. B. (2013). Research on Dust Migration Law and Its Removal Technology in Fully Mechanized Heading Face. MINING SAFETY \& ENVIRONMENTAL PROTECTION, 40, 25-28. http://doi.org/10.3969/j.issn.1008-4495.2013.03.009

\section{Copyright Disclaimer}

Copyright for this article is retained by the author(s), with first publication rights granted to the journal.

This is an open-access article distributed under the terms and conditions of the Creative Commons Attribution license (http://creativecommons.org/licenses/by/3.0/). 